Received: May 15, 2016

Revision received: July 5, 2016

Accepted: August 23, 2016

OnlineFirst: October 25, 2016
Copyright @ 2016 • Türkiye Yeşilay Cemiyeti

ISSN 2148-7286 elSSN 2149-1305

http://addicta.com.tr/

DOI 10.15805/addicta.2016.3.0101 • October 2016 • 3(2) • 1-20

Research Article

\title{
Online Addictions: Conceptualizations, Debates, and Controversies*
}

\author{
Mark D. Griffiths ${ }^{1}$ \\ Nottingham Trent University \\ Halley M. Pontes ${ }^{2}$ \\ Nottingham Trent University \\ Daria J. Kuss ${ }^{3}$ \\ Nottingham Trent University
}

\begin{abstract}
The activity of play has endured throughout human history and more recently, the Internet has emerged as a playground increasingly populated by gamblers, gamers, shoppers, and social networkers. Research suggests that a minority of online users experience symptoms traditionally associated with substance-related addictions, including mood modification, tolerance, conflict, and salience. Previous research suggests that a combination of individual, situational, and structural characteristics determine whether, and to what extent, individuals engage in various online activities. For instance, it is believed that access, affordability, and anonymity are critical factors that make the Internet viable for the acquisition, development, and maintenance of online addictions. Since the current scientific knowledge of online addiction is copious in scope and appears relatively complex, this paper examines a selection of the main debates in the field, the conceptualization of excessive online behavior as an addiction, and other key controversies.
\end{abstract}

Keywords

Internet addiction $\bullet$ Online addiction $\bullet$ Gaming addiction • Addiction debates $\bullet$ Addiction controversies

\footnotetext{
* This paper was presented at the 3th International Congress of Technology Addiction, Istanbul, May 3-4, 2015.

1 Correspondence to: Mark D. Griffiths (PhD), International Gaming Research Unit, Psychology Department, Nottingham Trent University, Burton Street, Nottingham NG1 4BU, United Kingdom. Email: mark.griffiths@ntu.ac.uk

2 International Gaming Research Unit, Psychology Department, Nottingham Trent University, Burton Street, Nottingham NG1 4BU, United Kingdom. Email: halley.pontes@ntu.ac.uk

3 International Gaming Research Unit, Psychology Department, Nottingham Trent University, Burton Street, Nottingham NG1 4BU, United Kingdom. Email: daria.kuss@ntu.ac.uk

Citation: Griffiths, M. D., Pontes, H. M., \& Kuss, D. J. (2016). Online addictions: Conceptualizations, debates, and controversies. Addicta: The Turkish Journal on Addictions, 3, 1-20. http://dx.doi.org/10.15805/addicta.2016.3.0101
} 
It has been alleged that pathologies exist among excessive Internet users and videogame players. For instance, Soper and Miller (1983) claimed "videogame addiction" was like any other behavioral addiction, and consisted of a compulsive behavioral involvement, a lack of interest in other activities, association mainly with other addicts, and physical and mental symptoms when attempting to stop the behavior (e.g., the "shakes"). Young (1998) argued a similar case for excessive Internet users. Such addictions have been termed "technological addictions" (Griffiths, 1995, 1996a), and have been operationally defined as non-chemical (behavioral) addictions that involve excessive human-machine interaction. They can either be passive (e.g., television) or active (e.g., videogames), and usually contain inducing and reinforcing features which may contribute to the promotion of addictive tendencies (Griffiths, 1995). Thus, technological addictions can be viewed as a subset of behavioral addictions (Marks, 1990), and feature core components of addiction first outlined by Brown (1993). Later, Griffiths (1996b; 2005a) further modified these components to include salience, mood modification, tolerance, withdrawal, conflict, and relapse (described below).

Arguably, three fundamental questions have underpinned research regarding online addictions: (i) What is addiction? (ii) Does Internet addiction (IA) or videogame addiction actually exist? (iii) If IA and videogame addiction exist, what are people actually addicted to? The first question continues to be much debated, both among psychologists within the field of addiction research and among those working in other disciplines. Griffiths (2005) has operationally defined addictive behavior as any behavior that features all of the core components of addiction. Griffiths contends that any behavior (e.g., videogame playing, Internet use) that fulfills these six criteria would be operationally defined as an addiction. In the case of Internet or videogame addiction, the criteria are:

- Salience. This occurs when Internet usage or playing videogames becomes the most important activity in a person's life; dominating their thinking (preoccupations and cognitive distortions), feelings (cravings), and behavior (deterioration of socialized behavior). For instance, even if not actually on the Internet or playing a videogame, the individual will be thinking about the next time that he or she will be.

- Mood modification. This refers to the subjective experiences that people report as a consequence of engaging in Internet use or videogame play, and can be seen as a coping strategy (i.e., they experience an arousing "buzz" or a "high" or, paradoxically, a tranquilizing feeling of "escape" or "numbing").

- Tolerance. This is the process whereby increasing amounts of Internet use or videogame play are required to achieve the former mood-modifying effects. In other words, people gradually build-up the amount of time they spend engaged in Internet use or playing videogames. 
- Withdrawal symptoms. These are the unpleasant feeling states and/or physical effects that occur when Internet use or videogame play is discontinued or suddenly reduced (e.g., shakiness, moodiness, or irritability).

- Conflict. This refers to the conflicts between the Internet user or videogame player and those around them "(e.g., interpersonal conflict), conflicts with other activities (e.g., job, schoolwork, social life, hobbies, and interests) or from within the individual themselves (intrapsychic conflict and/or subjective feelings of loss of control), which are caused by spending too much time engaged in Internet use or videogame play.

- Relapse. This is the tendency for repeated reversions to earlier patterns of Internet use or videogame play, and for even the most extreme patterns typical at the height of excessive Internet use or videogame play to be quickly restored after periods of abstinence or control.

Having operationally defined addiction, it is clear that Internet and videogame addictions do indeed exist, but that they affect only a small minority of users and players (including adolescents). There appears to be many people who use the Internet or play videogames to an excessive degree, but are not addicted as measured by these (or any other) criteria.

The third question is perhaps the most interesting and the most important when it comes to researching this field. What are people actually addicted to when they excessively use the Internet or play videogames? Is it the act of playing? Is it aspects of its specific style (i.e., an anonymous and disinhibiting activity)? Is it the specific types of games (aggressive games, strategy games, etc.)? This has led to much debate among those working in this field. Indeed, research exploring IA may lead to insights regarding videogame addiction, and vice versa. For instance, Young (1999a) has claimed that IA is a broad term covering a wide variety of behaviors and impulse control problems that are categorized by five specific subtypes:

- Cybersexual addiction: Compulsive use of adult websites for cybersex and cyberporn.

- Cyber-relationship addiction: Over-involvement in online relationships.

- Net compulsions: Obsessive online gambling, shopping, or day-trading.

- Information overload: Compulsive web surfing or database searches.

- Computer addiction: Obsessive computer game playing.

In reply to Young, Griffiths (1999a; 2000a) has argued that many excessive Internet users are not "Internet addicts" but rather use the Internet as a medium to fuel other addictions. Put very simply, gambling or videogame addicts who engage 
in their chosen behavior online are not addicted to the Internet, rather the Internet is just the place where they engage in the behavior. However, in contrast, there are case-study reports of individuals who appear to be addicted to the Internet itself (e.g., Griffiths, 1996a, 1998, 2000b; Young, 1998). These are usually people (and very often adolescents in their late teenage years) who use Internet chat rooms or play fantasy role-playing games (activities that they would not engage in except on the Internet itself).

These individuals take on other social personas and social identities to improve the way they feel about themselves. In such cases, the Internet may provide an alternative reality to users and allow them feelings of immersion and anonymity that may lead to an altered state of consciousness. This in itself may be highly psychologically and/or physiologically rewarding. Obviously, for those playing online videogames (theoretically a combination of both Internet use and videogame play) these speculations may provide insights into the potentially addictive nature of videogames.

\section{Internet Addiction: The Debates}

Over the last 15 years, research regarding various online addictions has greatly increased (Kuss, Griffiths, Karila, \& Billieux, 2014). Prior to the publication of the fifth edition of the Diagnostic and Statistical Manual of Mental Disorders (DSM-5) (American Psychiatric Association, 2013), there had been some debate as to whether IA should be introduced into the text as a separate disorder (Block, 2008; Petry \& O'Brien, 2013). Similarly, there has also been debate as to whether those researching the online addiction field should be researching generalized Internet use and/or the potentially addictive activities that can be engaged in on the Internet (e.g., gambling, video gaming, sex, and shopping) (Griffiths, 2000a). Following these debates, the Substance Use Disorder Work Group (SUDWG) recommended that the DSM-5 include a sub-type of problematic Internet use (i.e., Internet Gaming Disorder [IGD]) in Section 3 ("Emerging Measures and Models") as an area in need of future research before being included in subsequent editions of the DSM (Petry \& O'Brien, 2013). According to Petry and O'Brien (2013), IGD will not be included as a separate mental disorder until (i) its defining features have been identified, (ii) reliability and validity of specific IGD criteria have been obtained cross-culturally, (iii) prevalence rates have been determined in representative epidemiological samples around the world, and (iv) etiology and associated biological features have been evaluated.

Although there is now a rapidly growing body of literature on gaming addiction (Griffiths, Kuss, \& King, 2012), one of the key reasons that IGD was not included in the main text of the DSM-5 was that the SUDWG concluded that standard diagnostic criteria were not used to assess gaming addiction across these many studies. A 
review of instruments assessing problematic, pathological, and/or addictive gaming by King, Haagsma, Delfabbro, Gradisar, and Griffiths (2013) reported that 18 different screening instruments had been developed, and that these had been used in 63 quantitative studies comprising 58,415 participants. This comprehensive review identified both strengths and weaknesses of these instruments.

The main strengths of the instrumentation included (i) brevity and ease of scoring, (ii) excellent psychometric properties, such as convergent validity and internal consistency, and (iii) robust data that can aid the development of standardized norms for adolescent populations. However, the main weaknesses identified in the instrumentation included (i) core addiction indicators being inconsistent across studies, (iii) a general lack of any temporal dimension, (iii) inconsistent cut-off scores relating to clinical status, (iv) poor and/or inadequate inter-rater reliability and predictive validity, and (v) inconsistent dimensionality. A number of authors note that the criteria for IGD assessment tools are theoretically based upon a variety of different potentially problematic activities, including substance use disorders, pathological gambling, and/or other behavioral addiction criteria (King et al., 2013; Kuss, Griffiths, Karila, \& Billieux, 2014a; Petry \& O’Brien, 2013). Moreover, there are issues surrounding the settings in which diagnostic screens were used, as those used in clinical practice settings may require a different emphasis than those used in epidemiological, experimental, and neurobiological research settings (King et al., 2013; Koronczai et al., 2011).

The components and dimensions that comprise online gaming addiction outlined above are similar to the IGD criteria in Section 3 of the DSM-5. For instance, Griffiths' (2005) six addiction components directly map onto the nine proposed criteria for IGD (of which five or more need to be endorsed and result in clinically significant impairment). More specifically the nine criteria include: (i) preoccupation with Internet games [salience]; (ii) withdrawal symptoms when Internet gaming is taken away [withdrawal]; (iii) the need to spend increasing amounts of time engaged in Internet gaming [tolerance], (iv) unsuccessful attempts to control participation in Internet gaming [relapse/loss of control]; (v) loss of interest in hobbies and entertainment as a result of, and with the exception of, Internet gaming [conflict]; (vi) continued excessive use of Internet games despite knowledge of psychosocial problems [conflict]; (vii) deception of family members, therapists, or others regarding the amount of Internet gaming [conflict]; (viii) use of the Internet gaming to escape or relieve a negative mood [mood modification]; and (ix) loss of a significant relationship, job, or educational or career opportunity because of participation in Internet games [conflict]. Moreover, Griffiths' addiction components model has been verified in the context of Internet use (e.g., Kuss, Shorter, van Rooij, Griffiths, \& Schoenmakers, 2014b; Kuss, Shorter, van Rooij, van de Mheen, \& Griffiths, 2014c). 
The fact that IGD was included in Section 3 of the DSM-5 appears to have been well received by researchers and clinicians in the gaming addiction field (and by those individuals that have sought treatment for such disorders and had their experiences psychiatrically validated, making them feel less stigmatized). However, for IGD to be included in the section "Substance-Related and Addictive Disorders" along with "Gambling Disorder," the gaming addiction field must unite and adopt the same assessment measures so that reliable comparisons can be made across different demographic groups and cultures. For epidemiological purposes, Koronczai and colleagues (2011) asserted that the most appropriate measures in assessing online addictions (including Internet gaming) should meet six requirements. Such an instrument should have (i) brevity (to make surveys as short as possible and help overcome question fatigue); (ii) comprehensiveness (to examine all core aspects of problematic gaming); (iii) reliability and validity across age groups (e.g., adolescents vs. adults); (iv) reliability and validity across data collection methods (e.g., online, face-to-face interview, or paper-and-pencil); (v) cross-cultural reliability and validity; and (vi) clinical validation. It was also noted that an ideal assessment instrument should serve as the basis for defining adequate cut-off scores in terms of both specificity and sensitivity. In addition to further epidemiological and clinical research, further research is also needed on the neurobiology of IGD.

\section{Generic Risk Factors that may Facilitate Online Addictions}

A number of factors make online activities, such as gaming, gambling, shopping, and sex, potentially enticing and/or addictive. Furthermore, virtual environments have the potential to provide short-term comfort, excitement, and/or distraction. Some researchers have attempted to explain why the Internet can be so alluring. In particular, Cooper (1998) proposed the Triple A Engine (access, affordability, and anonymity), which he claimed helps to understand the power and attraction of the Internet for sexual pursuits. Young (1999b) also claimed to have developed a variant of the Triple A Engine that she called the ACE model (anonymity, convenience, and escape). Outlined below are some of the main variables that may account for acquisition and maintenance of some online addictive behaviors (anonymity, convenience, escape, dissociation/immersion, accessibility, disinhibition, and social acceptability) (Griffiths, 2003).

Accessibility-Access to the Internet is now commonplace in both the home and/or workplace. Given that the prevalence of behaviors is strongly correlated with increased access to the activity (Griffiths, 2003), it is not surprising that the development of regular online use is increasing across the general population. However, increased accessibility may also lead to increased problems. Research regarding socially acceptable, but potentially addictive substances and behaviors (e.g., drinking alcohol, 
gambling), has demonstrated that increased accessibility generally leads to increased uptake (i.e., regular use) and that this usually leads to an increase in problems, although the increase may not be proportional (Griffiths, 1999b).

- Affordability-Given the wide accessibility of the Internet, it is now becoming less expensive to use the online services offered. Almost all Internet service providers now provide flat-rate monthly fees rather than charging by the minute (as was the norm in the late 1990's).

- Anonymity-The anonymity of the Internet allows users to engage privately in their favored activities without the fear of stigma (Griffiths, 2003). This anonymity may also provide the user with a greater sense of perceived control over the content, tone, and nature of the online experience. Anonymity may also increase feelings of comfort since there is a decreased ability to look for, and thus detect, signs of insincerity, disapproval, or judgment in facial expressions typical in face-to-face interactions.

- Convenience-Interactive online applications, such as e-mail, chat rooms, newsgroups, or role-playing games, provide convenient mediums to engage in online behaviors. Online behaviors will usually occur in the familiar and comfortable environment of the home or workplace, thus reducing the feeling of risk and allowing more potentially addictive, adventurous behaviors (Griffiths, 2003).

- Escape-For some, the primary reinforcement to engage in online activities is the gratification they experience online. However, the experience of engaging in various online applications (e.g., gaming, gambling, shopping, or sex), may be reinforced through a subjectively and/or objectively experienced "high". The pursuit of mood-modifying experiences is characteristic of addictions (Griffiths, 2005). The mood-modifying experience has the potential to provide an emotional or mental escape and further serves to reinforce the behavior. Excessive involvement in this escapist online activity may lead to may lead to addiction as online behaviors can provide a potent behavior can provide a potent escape from the stresses and strains of real life (Griffiths, 2003).

- Immersion/Dissociation-The Internet can provide feelings of dissociation and immersion that may facilitate feelings of escape (Griffiths, 2003). Dissociation and immersion can involve many different types of feelings, including losing track of time, feeling like someone else, blacking out, and being in a trance-like state (Griffiths, Wood, Parke, \& Parke, 2006). In the case of Internet gambling for instance, all of these feelings all of these feelings may lead to longer Internet use either because "time flies when you are having fun" or because the psychological feelings of being in an immersive or dissociative state act as reinforcement (Griffiths, 2003). 
- Disinhibition-This is clearly one of the Internet's key appeals as there is little doubt that the Internet reduces inhibition (Joinson, 1998; Suler, 2004). Online users appear to open up more quickly online and reveal themselves emotionally faster than in the offline world. For the Internet user, being in a disinhibited environment may lead to prolonged online sessions (Griffiths, 2003).

- Social acceptability-The social acceptability of online interaction is another factor to consider in this context. What is interesting is how the perception of online activity has changed over the last 20 years (e.g., the "nerdish" image of the Internet is almost obsolete) (Griffiths, 2010a). It may also be a sign of increased acceptance as young children are exposed to technology earlier and become accustomed to using computers as tools for socializing. For instance, laying the foundation for an online relationship in this way has become more socially acceptable, and rather than acting as societal misfits, as has often been claimed, individuals are simply using technology as another tool in their social armory (Griffiths, 2010a).

\section{Internet Addiction: A Brief Overview}

Investigating the incidence and prevalence rates of IA in the general population is paramount to assessing the demand for consulting, treatments, and preventive measures (Wartberg, Kriston, Kammerl, Petersen, \& Thomasius, 2015). However, IA research that attempts to estimate its prevalence rate is usually faced with several methodological shortcomings. On the one hand, there are currently no consensual criteria established for IA, which directly affects the adequacy, reliability, and validity of studies using inconsistent diagnostic instruments to assess this phenomenon (Weinstein \& Lejoyeux, 2010). On the other hand, despite the difficulties concerning the diagnosis and the heterogeneity of instruments to assess IA, most studies reporting prevalence rates of IA usually suffer from sampling selection biases due to systematic use of non-probability sampling techniques (e.g., convenience samples) and overreliance on specific samples (e.g., adolescents or adults) (Rumpf et al., 2014). Consequently, these two issues compromise the validity of most prevalence studies, while also limiting possible comparisons of prevalence rates across different cultural contexts. Irrespective of the assessment instrument, IA appears to be systematically associated with the amount of time spent online. Nevertheless, a number of authors have indicated that excessive Internet use does not necessarily mean that it is problematic (Griffiths, 2010b).

In a systematic review, Kuss, Griffiths, Karila, and Billieux (2014) reviewed 68 epidemiological studies of IA with a minimum of 1,000 participants published after the year 2000. They reported that no gold standard of IA classification existed as they identified 21 different assessment instruments that had been used to assess IA in the 
literature. These instruments adopted official criteria for substance use disorders and/ or pathological gambling, the majority of which had no (or few) criteria relevant for an addiction diagnosis, time spent online, or resulting problems. The review reported prevalence rates differing as a consequence of different assessment tools and cut-offs, ranging from $0.8 \%$ in Italy to $26.7 \%$ in Hong Kong. IA was associated with a number of sociodemographic factors (being male), type of Internet use (gaming, sex), and psychosocial factors, as well as comorbid symptoms and disorders in adolescents and adults (e.g., low self-control, impulsivity, and sensation-seeking). Overall, the results indicated that a number of core symptoms (i.e., compulsive use, negative outcomes, and salience) appear relevant for diagnosis, and conceptualization of IA as a syndrome with similar etiology and components, but different expressions of addictions.

Prevalence rates of IA have been provided by recent review studies. For instance, Cheng and $\mathrm{Li}$ (2014) conducted a meta-analysis in order to estimate prevalence rates of IA across several countries by searching for evidence stemming from empirical studies published between 1996 and 2012. In the study, the authors identified 164 IA prevalence rates published across 80 studies from 31 nations across seven world regions. The results showed a global prevalence of IA of approximately $6 \%$, with the highest rates found in the Middle East (10.9\%) and lower rates found in Northern and Western Europe (2.6\%). The authors also reported that poor quality of life was associated with greater prevalence rates of IA.

More recently, Pontes, Kuss, and Griffiths (2015) reviewed epidemiological data published between January 2014 and February 2015 from 12 studies with nationally representative samples. Prevalence rates of IA ranged from a minimum of $0 \%$ in one study (Iran) to a maximum of $18.7 \%$ in another (Taiwan). While all 12 studies used cross-sectional designs to assess prevalence rates in different countries, significant heterogeneity in the assessment of IA was found alongside arbitrariness in terms of the cut-off points adopted to ascertain prevalence rates, even when researchers had used the same instrument. They also noted that almost half of the studies included (5 out of 12) did not assess IA with a psychometrically validated instrument. With the exception of one study, all remaining studies provided data on adolescent samples only, thus hampering the degree of generalizability of extant prevalence rates to other important segments of the general population, such as young children and adults. Regarding the differences in prevalence rates of IA among males and females, the review found that almost half of the studies reported higher prevalence rates among males, whereas only one study found higher rates in females. 


\section{Online Gaming Addiction: A Brief Overview}

A number of papers (e.g., Kuss \& Griffiths, 2012a, 2012b; Pontes \& Griffiths, 2015) have systematically reviewed prevalence studies on online gaming addiction.

There have now been over 100 empirical studies reporting prevalence data, although the overwhelming majority have used self-selected (non-representative) samples. Review papers (Kuss \& Griffiths, 2012a, 2012b; Pontes \& Griffiths, 2015) have argued that online gaming addiction follows a continuum, and that gaming addiction is associated with various personality traits (e.g., introversion, sensation-seeking, neuroticism, state/trait anxiety, low emotional intelligence, and social inhibition). As with prevalence studies concerning IA, terminologies and assessment of gaming addiction were variable (e.g., problem videogame playing, problematic online game use, videogame addiction, and online gaming addiction). Taking the literature as a whole, excessive (problematic) engagement was found in approximately $8-12 \%$ of young persons, whereas addiction seems to be present in $2-5 \%$ of children, teenagers, and students (Kuss \& Griffiths, 2012a, 2012b).

More credence should be given to the few national gaming addiction prevalence surveys that have been published as studies that have estimated prevalence rates based upon representative samples usually find lower, more realistic, and robust prevalence rates than studies using self-selected samples. Surveys using nationally representative samples have reported rates of problematic gaming as $8.5 \%$ in American youth aged 8-18 years (Gentile, 2009), 1.2\% in German adolescents aged 13-18 years (Rehbein, Kliem, Baier, Mößle, \& Petry, 2015), 5.5\% in Dutch adolescents aged 13-20 years, and $5.4 \%$ in Dutch adults (Lemmens, Valkenburg, \& Gentile, 2015), 4.3\% in Hungarian adolescents aged 15-16 years (Király, Nagygyörgy, Griffiths, \& Demetrovics, 2014; Király et al., 2014), 1.4\% in Norwegian gamers (Wittek et al., 2016), 1.6\% in youth from seven European countries aged 14-17 years (Müller et al., 2015), and 2.5\% in Slovenian adolescents aged 12-16 years (Pontes, Macur, \& Griffiths, 2016).

A review by Griffiths, Kuss, and King (2012) noted that a number of studies had examined the role of different personality, comorbidity, and biological factors and their association with gaming addiction. In relation to personality traits, the review reported that gaming addiction has been shown to be associated with increased neuroticism, aggression and hostility, avoidant and schizoid interpersonal tendencies, loneliness and introversion, social inhibition, boredom inclination, sensation-seeking, diminished agreeableness, diminished self-control and narcissistic personality traits, low self-esteem, state and trait anxiety, and low emotional intelligence. Considering the relatively high frequency of co-occurring personality, comorbidity, and biological factors, it is hard to assess the etiological significance of these associations with gaming addiction as they may not be unique to the disorder. Therefore, further research is needed. 
The same review reported gaming addiction to be associated with a variety of comorbid disorders. These include attention deficit hyperactivity disorder, symptoms of generalized anxiety disorder, panic disorder, depression, social phobia, school phobia, and various psychosomatic symptoms. Irrespective of whether problematic online gaming can be classed as an addiction, Griffiths et al. (2012) noted there are now a relatively large number of studies all indicating that excessive online gaming can lead to a wide variety of negative psychosocial consequences for a minority of affected individuals. These include sacrificing work, education, hobbies, socializing, time with partner/family, and sleep, as well as increased stress, an absence of reallife relationships, lower psychosocial weelbeing and loneliness, poorer social skills, decreased academic achievement, increased inattention, aggressive/oppositional behavior and hostility, maladaptive coping, decreases in verbal memory performance, maladaptive cognitions, and suicidal ideation. From a neurobiological perspective, a systematic review of 18 neuroimaging studies examining both IA and gaming addiction (Kuss \& Griffiths, 2012c) noted:

These studies provide compelling evidence for the similarities between different types of addictions, notably substance-related addictions and Internet and gaming addiction, on a variety of levels. On the molecular level, Internet addiction is characterized by an overall reward deficiency that entails decreased dopaminergic activity. On the level of neural circuitry, Internet and gaming addiction lead to neuroadaptation and structural changes that occur as a consequence of prolonged increased activity in brain areas associated with addiction. On a behavioral level, Internet and gaming addicts appear to be constricted with regards to their cognitive functioning in various domains (p. 347).

\section{Conclusion}

Based upon the published empirical studies, and particularly those published over the last decade, it appears that in extreme cases, excessive online use can have potentially damaging effects for individuals who appear to display compulsive and/ or addictive behaviors similar to other more traditional addictions. However, the field has been hindered by the use of inconsistent and non-standardized criteria to assess and identify problematic and/or addictive online use. Furthermore, the recruitment methods used in the majority of studies have serious sampling biases with an overreliance on self-selected samples.

Clearly, a number of gaps in the current understanding of problematic and/or addictive online behaviors exist. There is a need for epidemiological research to determine the clinical course, incidence, and prevalence of clinically significant problems associated with online addictions among the broader population. Overall, 
there are too few clinical studies that describe the unique features and symptoms of problematic online use and/or online addictions. A majority of studies tend to examine problematic online use from the perspective of the individual and disregard situational and structural characteristics of the online use itself as well as the context of the behavior, as highlighted by Kuss (2013).

Viewing the literature as a whole, online addictions do exist (depending upon the addiction criteria used). Although time spent online correlates with IA, excessive use can be non-problematic. The medium may be more harmful for susceptible individuals (e.g., youth) and most research suggests that IAs are specific (e.g., IGD) rather than generalized. For a small minority, the Internet (in and of itself) may be addictive, but further empirical research is required.

\section{References}

American Psychiatric Association. (2013). Diagnostic and statistical manual of mental disorders Text revision (5th ed.). Washington, DC: Author.

Block, J. J. (2008). Issues for DSM-V: Internet addiction. American Journal of Psychiatry, 165, 306-307.

Brown, R. I. F. (1993). Some contributions of the study of gambling to the study of other addictions. In W. R. Eadington \& J. A. Cornelius (Eds.), Gambling behavior and problem gambling (pp. 241-272). Reno, NV: University of Nevada Press.

Cheng, C., \& Li, A. Y-L. (2014). Internet addiction prevalence and quality of (real) life: A metaanalysis of 31 nations across seven world regions. Cyberpsychology, Behavior and Social Networking, 17, 755-760.

Cooper, A. (1998). Sexuality and the Internet: Surfing into the new millennium. CyberPsychology and Behavior, 1, 181-187.

Gentile, D. (2009). Pathological video-game use among youth ages 8 to 18: A national study. Psychological Science, 20, 594-602.

Griffiths, M. D. (1995). Technological addictions. Clinical Psychology Forum, 76, 14-19.

Griffiths, M. D. (1996a). Internet “addiction”: An issue for clinical psychology? Clinical Psychology Forum, 97, 32-36.

Griffiths, M. D. (1996b). Behavioral addictions: An issue for everybody? Journal of Workplace Learning, 8(3), 19-25.

Griffiths, M. D. (1999a). Internet addiction: Internet fuels other addictions. Student British Medical Journal, 7, 428-429.

Griffiths, M. D. (1999b). Gambling technologies: Prospects for problem gambling. Journal of Gambling Studies, 15, 265-283.

Griffiths, M. D. (2000a). Internet addiction - time to be taken seriously? Addiction Research, 8, 413-418.

Griffiths, M. D. (2000b). Does Internet and computer "addiction" exist? Some case study evidence. CyberPsychology and Behavior, 3, 211-218. 
Griffiths, M. D. (2003). Internet gambling: Issues, concerns and recommendations. CyberPsychology and Behavior, 6, 557-568.

Griffiths, M. D. (2010a). Internet abuse and internet addiction in the workplace. Journal of Workplace Learning, 7, 463-472.

Griffiths, M. D. (2010b). The role of context in online gaming excess and addiction: Some case study evidence. International Journal of Mental Health and Addiction, 8, 119-125.

Griffiths, M. D., Kuss, D. J., \& King, D. L. (2012). Video game addiction: Past, present and future. Current Psychiatry Reviews, 8, 308-318.

Griffiths, M. D., Wood, R. T. A., Parke, J., \& Parke, A. (2006). Dissociative states in problem gambling. In C. Allcock (Ed.), Current issues related to dissociation (pp. 27-37). Melbourne: Australian Gaming Council.

Joinson, A. (1998). Causes and implications of disinhibited behavior on the Internet. In J. Gackenback (Ed.), Psychology and the internet: Intrapersonal, interpersonal, and transpersonal implications (pp. 43-60). New York, NY: Academic Press.

King, D. L., Haagsma, M. C., Delfabbro, P. H., Gradisar, M. S., \& Griffiths, M. D. (2013). Toward a consensus definition of pathological video-gaming: A systematic review of psychometric assessment tools. Clinical Psychology Review, 33, 331-342.

Király, O., Griffiths, M. D., Urbán, R., Farkas, J., Kökönyei, G., Elekes, Z., ... Demetrovics, Z. (2014). Problematic Internet use and problematic online gaming are not the same: Findings from a large nationally representative adolescent sample. Cyberpsychology, Behavior, and Social Networking, 17, 749-754.

Király, O., Nagygyörgy, K., Griffiths, M. D., \& Demetrovics, Z. (2014). Problematic online gaming. In K. Rosenberg \& L. Feder (Eds.), Behavioral addictions: Criteria, evidence and treatment (pp. 61-95). New York, NY: Elsevier.

Kuss, D. J., \& Griffiths, M. D. (2012a). Online gaming addiction in adolescence: A literature review of empirical research. Journal of Behavioral Addictions, 1, 3-22.

Kuss, D. J., \& Griffiths, M. D. (2012b). Online gaming addiction: A systematic review. International Journal of Mental Health and Addiction, 10, 278-296.

Kuss, D. J., \& Griffiths, M. D. (2012c). Internet and gaming addiction: A systematic literature review of neuroimaging studies. Brain Sciences, 2, 347-374.

Kuss, D. J. (2013). Internet gaming addiction: Current perspectives. Psychology Research and Behavior Management, 6, 125-137.

Kuss, D. J., Griffiths, M. D., Karila, L., \& Billieux, J. (2014a). Internet addiction: A systematic review of epidemiological research for the last decade. Current Pharmaceutical Design, 20, 4026-4052.

Kuss, D. J., Shorter, G. W., van Rooij, A. J., Griffiths, M. D., \& Schoenmakers, T. (2014b). Assessing internet addiction using the parsimonious internet addiction components model - A preliminary study. International Journal of Mental Health and Addiction, 12(3), 351-366.

Kuss, D. J., Shorter, G. W., van Rooij, A. J., van de Mheen, D., \& Griffiths, M. D. (2014c). The internet addiction components model and personality: Establishing construct validity via a nomological network. Computers in Human Behavior, 39, 312-321.

Koronczai, B., Urban, R., Kokonyei, G., Paksi, B., Papp, K., Kun, B., ... Demetrovics, Z. (2011). Confirmation of the three-factor model of problematic internet use on off-line adolescent and adult samples. Cyberpsychology, Behavior and Social Networking, 14, 657-664. 
Lemmens, J. S., Valkenburg, P. M., \& Gentile, D. A. (2015). The Internet Gaming Disorder Scale. Psychological Assessment, 27, 567-582.

Marks, I. (1990). Non-chemical (behavioural) addictions. British Journal of Addiction, 85, 13891394.

Müller, K. W., Janikian, M., Dreier, M., Wölfling, K., Beutel, M. E., Tzavara, C., ... Tsitsika, A. (2015). Regular gaming behavior and internet gaming disorder in European adolescents: Results from a cross-national representative survey of prevalence, predictors, and psychopathological correlates. European Child and Adolescent Psychiatry, 24, 565-574.

Petry, N. M., \& O'Brien, C. P. (2013). Internet gaming disorder and the DSM-5. Addiction, 108, $1186-1187$.

Pontes, H. M., \& Griffiths, M. D. (2015). Internet gaming disorder and its associated cognitions and cognitive-related impairments: A systematic review using PRISMA guidelines. Revista Argentina de Ciencias del Comportamiento, 7(3), 102-118.

Pontes, H. M., Macur, M., \& Griffiths, M. D. (2016). Internet gaming disorder among Slovenian primary schoolchildren: Findings from a nationally representative sample of adolescents. Journal of Behavioral Addictions, 5, 304-310.

Rehbein, F., Kliem, S., Baier, D., Mößle, T., \& Petry, N. M. (2015). Prevalence of internet gaming disorder in German adolescents: Diagnostic contribution of the nine DSM-5 criteria in a statewide representative sample. Addiction, 110, 842-851.

Rumpf, H. J., Vermulst, A. A., Bischof, A, Kastirke N., Gürtler D., ... Meyer, C. (2014). Occurrence of internet addiction in a general population sample: A latent class analysis. European Addiction Research, 20, 159-166.

Soper, W. B., \& Miller, M. J. (1983). Junk time junkies: An emerging addiction among students. School Counselor, 31, 40-43.

Suler, J. (2004). The online disinhibition effect. CyberPsychology and Behavior, 7, 321-326.

Wartberg, L., Kriston, L., Kammerl, R., Petersen, K. U., \& Thomasius, R. (2015). Prevalence of pathological internet use in a representative German sample of adolescents: Results of a latent profile analysis. Psychopathology, 48, 25-30.

Weinstein, A., \& Lejoyeux, M. (2010). Internet addiction or excessive internet use. American Journal of Drug and Alcohol Abuse, 36, 277-283.

Wittek, C. T., Finserås, T. R., Pallesen, S., Mentzoni, R. A., Hanss, D., Griffiths, M. D., \& Molde, H. (2016). Prevalence and predictors of video game addiction: A study based on a national representative sample of gamers. International Journal of Mental Health and Addiction, 14, $672-685$.

Young, K. (1998). Caught in the net: How to recognize the signs of internet addiction and a winning strategy for recovery. New York, NY: Wiley.

Young, K. (1999a). Internet addiction: Evaluation and treatment. Student British Medical Journal, 7, 351-352.

Young, K. (1999b, August). Cyber-disorders: The mental illness concern for the millennium. Paper presented at the 108th Annual Meeting of the American Psychological Association, Boston, MA. 